\title{
Information And Communication Technology Literacy Among Academics In Ahmadu Bello University Zaria
}

\section{By}

\section{Umar Babangida Dangani and Prof. Zakari Mohammed}

\begin{abstract}
The study was carried out to assess the Information and Communication Technology Literacy among Academics in A.B.U., Zaria. Two research questions were raised and answered and 2 hypothesis were also formulated and tested at $\alpha 0.05$. The research questions sought to find the available ICT gadget and fluency of the academics with the ICT. A survey research design was employed for the study. Proportionate stratified random sampling was used to select a sample size of 30\% (523) from a population of 1,744. ICT Literacy scale - developed by academy horizon in education in USA was adopted as data collection instruments. Data collected from the research questions were analyzed using frequency count and charts, while null hypothesis 1 and 2 were tested using ANOVA and PPMC respectively. The research discovered that computer system, CDRom, flash drives, printers, scanners and mobile phone were most available ICT facilities in ABU Zaria. It was also discovered that there is no significant relationship between ICT literacy and Academic qualifications. The research conclude that ICT literacy is necessary in the scheme of things in the $21^{\text {st }}$ century. It was finally recommended provision of state of the arts ICT facilities in all faculties and staff offices in the university.
\end{abstract}

\section{Introduction}

Information and communication technology (ICT) is often been described as the technology where computers and telecommunication devices are used for information gathering/acquisition, processing, storage, retrieval and dissemination to the relevant users. The use of information communication technologies (ICTs) in teaching and research by academics has arisen because of the increased demand for information and increasing number of information sources. The information revolution and the extraordinary increase in the spread of knowledge have given birth to a new era-- of knowledge and information which affects directly all spheres of organizations' life cycle. Based on this trend, individuals, organizations and governments worldwide have recognized the role that Information and Communication Technologies could play in fostering growth and development.

Howell and Lundall (2000) viewed ICTs to encompass all forms of technology used to create, store, process and use information in its various forms (data, voice, image, multi-media presentations and other forms including those not yet conceived) and which enable, facilitate and support communication. More specifically, ICTs also include telephone, mobile phone, private automatic box exchange (PABX), photocopier, scanners, fax machines, close circuit television sets, cameras, personal digital assistants (PDAs) conventional digital camera, microwave link systems and very small aperture terminal (V-Sat), computer, magnetic tape, CD-ROMs, DVDs and the Internet.

Today, ICTs have become a driving force in the academia. It provides a platform whereby academics can generate, store, retrieve, preserve and transmit information within and outside their organization.

Thus, the new ICTs have increased the information-processing capacity of the economy at an exponential rate, while simultaneously enhancing the salience of knowledge-based inputs in every aspect of production. Also, it enables organizations to dramatically reduce the cost of generating, storing, transmitting and processing information throughout all sectors of the economy.

\section{Statement of the Problem}

Technology is changing our environment at an ever increasing rate, while such technology provides improved opportunities for accessing, retrieval and interpretation of information, realizing these opportunities requires knowledge and skills that are not easily acquired and are even more difficult to keep up to date. Technology in academic environment improves physical access to information but does not necessarily improve intellectual access. It provides a greater opportunity for peer learning and communication but the time to read, think and write cannot be reduced. It also provides a mechanism for the networking of invisible colleges. However, hardware and software changes and copyright issues create a high risk academic environment in which applications are experimental and may not be lasting. Shift from print to electronic base resources requires information technology skills for it use and many academics in Nigerian universities cannot use Internet and other ICT facilities independently. They have to resort to the use of café's attendant for most of their searches and online transactions. There is also a general belief that whatever is on the Internet is of high quality or superior to the print documents. This vast amount 
of information on the Internet that is of less value requires people to validate and assess information to verify its reliability. Many of the academics do not have clear understanding of the relationship between information sources, their appropriateness and reliability and also how to make intelligent choice among them. Similarly, it was also noticed by Deborah (1998) that large numbers of students are leaving post graduate schools in Nigerian universities without the necessary skills to cope in information based society. These graduates are in turn recruited by universities as academic staff. It was also observed that a majority of searches on the internet in Ahmadu Bello University Zaria were Google searches, this indicate either lack of awareness of other search tools or low level in IT literacy

However, it is in the light of the aforementioned problems that this research was set to assess the Information and Communication Technology Literacy of Academics in Ahmadu Bello University Zaria.

\section{Research Questions}

This study has provided answers to the following research questions:

1. What type of Information Communication Technology facilities is available for teaching and research by the Academics?

2. To what extent are the Academics in Ahmadu Bello University Zaria information and communication Technology literate?

\section{Research Hypothesis}

The research tested the following null hypothesis: Ho1. There is no significant difference among humanities, scientist, applied scientist and social scientist in their level of information and communication technology literacy.

Ho2. There is no significant relationship between academic qualification of the academics and their level of ICT literacy in Ahmadu Bello University Zaria.

\section{The Concept of ICT}

The information and communication technology (ICT) is a new development which brings together the technologies of micro electronics, computing and telecommunications. It is sometimes referred to as the science of information handling. Teague (1985) define ICT as the convergence of technologies that are useful and profitable in their approach to information storage, transfer and retrieval. Thompson (1982) defines ICTs as the 'potential combination of computers, in which information could be stored and processed, and telecommunication by means by which information can be transmitted to anybody anywhere in the world". He further observed that: "There are three key component of it, first new way to store information compactly and deeply, photographic microfilms of various kinds, magnetic storage in tapes and discs, optical storage and video disks, etc. Secondly new mechanisms to manipulate, scan and search such stored information. The large Scale computer, microprocessor, minicomputer and related devices. Thirdly, new facilities for cheap and rapid transmission of information over long distances, telecommunication system and networks”.

Information and communication technology constitute the factors that speed the development of all other associates technologies. Marghalani (1987) defines ICTS as the application of computer and other technology to the acquisition, organization, storage, retrieval and dissemination.

However, ICT offers new forms of information storage and retrieval system. It originated with the coming together of three (3) technologies: Microelectronics, computer and telecommunication. Generally speaking ICT has progressed to the point where it is possible to plan and manage electronically stored and transmitted information and make it available to users at reduce cost.

\section{Information and Communication Technology and Information Literacy}

Just as $16^{\text {th }}$ century navigators were required to read the stars and understand tides to find their way, today's Academics must learn to become information navigators, finding their way through print, graphic, electronic and visual media to discover and interpret relevant information. They must become critical thinkers and analyzers using technology to access, interpret and evaluate the quality and appropriateness of the information they have discovered. And, as navigators of old drew maps to share what they found with others, similarly the today's Academics must learn how to create and share knowledge using all the forms of media and telecommunications to communicate their ideas, engage in discourse, and solve problems. This statement justifies the need for academics to be technology literate. Educators must prepare themselves for the future by learning computer skills, educators and the general public widely accept the premise that academics must be technologically competent to be successful today and in the future, however, competence with technology must be set within the context of information literacy. 
Drucker(1992). Argues that "executives have become computer literate... but not many executives are information literate". Being able to use computers is not enough. Executives must be able to apply computer skills to real situations and real needs. They must be able to identify information problems and locate, use, synthesize and evaluate information in relation to those problems.

Information technology affects everyone. Today's successful companies focus on meaningful uses of information technology and hire employees who are able to apply technology to a range of situations. It is the responsibility of the educational system to develop academics that are technologically literate but also information literate. Academics must know how to use technology to solve information problems. The OECD through its International Adult Literacy Survey (IALS) project has identified a correlation between ICT skills and information literacy. They note that those with ICT skills are likely to have higher literacy levels and report that this relationship applies both between countries with high and low ICT access and also within countries. For instance, they report that fifteen year olds with access to home computers have higher reading skills than those without home access (OECD 2005:184).

The World Summit on the information Society (WSIS) raised concern on the digital divide between nations. This divide is also evident between regions within many nations. A notable example is the divide between rural and urban communities, but the digital divide is also evident within all countries between affluent people and those in relative poverty. In many countries, women report less access to ICT and less ICT skills, OICD, (2005:193). This may be the case also in relation to other forms of information supply. Initiatives to address such differences in access to information are important since access is a prerequisite to IL practice.

\section{Methodology}

A survey research design was adopted for the study. The population of the study was made up of 1744 Academics in the 12 faculties, 82 Departments, 7 libraries, 3 centres, 3 institutes and 3 Divisional Agricultural Colleges. Proportionate stratified random sampling was used to select a sample of 533 (30\%). ICT literacy Scale approved by Technology Horizon in education in June 2003 in USA was used as data Collection instrument. Data that relate to the research questions were analyzed using frequency count and percentages, while Null Hypotheses 1 and 2 were tested using One Way ANOVA and Pearson Product Moment Correlation respectively. They were all tested at $\alpha$ 0.05 and certain degree of freedoms

\section{The findings}

\section{Available ICT Facilities in Ahmadu Bello} University Zaria

This is to find out the types of ICTs available in Ahmadu Bello University Zaria. A list of ICTs was given to respondents and they were asked to tick as many as possible as the table shows below:

1.1 Information Communication Technology available Ahmadu

\begin{tabular}{|l|l|}
\hline Information Communication Technology Facilities Available & Available \\
\hline Computer system, & $\sqrt{ }$ \\
\hline Telephone & $\sqrt{ }$ \\
\hline Networking & $\sqrt{ }$ \\
\hline CD ROMS disk, flash drive & $\sqrt{ }$ \\
\hline Intercom & $\mathrm{X}$ \\
\hline Web CT & $\mathrm{X}$ \\
\hline printers, scanners, & $\sqrt{ }$ \\
\hline Films strips, slides, & $\sqrt{ }$ \\
\hline Internet access from the faculty & $\sqrt{ }$ \\
\hline Mobile phone & $\sqrt{ }$ \\
\hline Optical disk & $\mathrm{X}$ \\
\hline Fax machine & $\mathrm{X}$ \\
\hline Photocopies & $\sqrt{ }$ \\
\hline Personal digital Assistants (PDAs & $\mathrm{X}$ \\
\hline Intranet & $\mathrm{X}$ \\
\hline
\end{tabular}


From the table above, it was discovered that computer systems, CD-Rom, Flash drives, printers, Scanners and Mobile phones were the most available ICT facilities used and probably the most frequently used ICT facilities by Academics in A.B.U Zaria for teaching and research. However, the research discover the total absence of Web CT, Optical disk, Fax machine, Intranet and intercom in ABU Zaria as tools for teaching and research.

This result is unexpected, because academics are expected to be aware and use web ICT to teach or take classes online.

\section{Information and Communication Technology Literacy}

Today academics do not only use computers but also have laptops, wireless laptops, and PCs. In addition, we have the world wide web (WWW), scanners, Compact Disc burners, USB Drives, digital cameras and digital video cameras, Personal Digiatal Assistants, as well as video and DVD players and more of the Academics use variety of tools including video, e-mail, desktop publishing, online programs such as web CT and Black board as well as video conferencing to teach.

A comprehensive list of the ICT skills (twenty in number) approved by Technology Horizon in education in June 2003 in USA was provided for the academics in ABU Zaria to indicate their fluency in them. Table 4.18 below presents fluency of academics with information and Communication technology skills.

Table 2: Fluency with Information and Communication Technology

\begin{tabular}{|c|c|c|c|c|}
\hline S/No & ICT Skills & Very fluent & Fluent & Not Fluent \\
\hline 1 & Spreadsheet Skills & 71(13.9) & 181(30.5) & $258(50.6)$ \\
\hline 2 & Database skills & 68(13.3) & 173(33.9) & $269(52.7)$ \\
\hline 3 & Electronic Presentation skills & $85(16.7)$ & $157(30.8)$ & 268(52.5) \\
\hline 4 & Web Navigation skills & $96(18.8)$ & $153(30.0)$ & $261(51.2)$ \\
\hline 5 & Word processing skills & $82(16.1)$ & 277(54.3) & $151(29.6)$ \\
\hline 6 & Website design skills & $97(19.0)$ & $154(30.2)$ & $259(50.8)$ \\
\hline 7 & E-mail management skills & $71(13.9)$ & $258(50.6)$ & 181(35.5) \\
\hline 8 & Digital cameras & 101(19.8) & 195(38.2) & $214(42.0)$ \\
\hline 9 & Computer Network knowledge & $67(13.1)$ & 162(31.8) & $181(55.1)$ \\
\hline 10 & File management and window explorer & $77(15.1)$ & 264(51.8) & 169(33.1) \\
\hline 11 & $\begin{array}{l}\text { Downloading software from the web (including e- } \\
\text { books) }\end{array}$ & 83(16.3) & 238(46.7) & 189(37.0) \\
\hline 12 & Installation of software into a computer system & $11(2.2)$ & 162(31.8) & $337(66.1)$ \\
\hline 13 & Web CT or Blackboard teaching skills & $02(0.4)$ & $03(0.6)$ & $505(99.0)$ \\
\hline 14 & Video conferencing skills & $14(2.7)$ & $26(5.1)$ & $470(92.2)$ \\
\hline 15 & $\begin{array}{l}\text { Computer related storage device (knowledge in } \\
\text { discs, CDs, USB drives, ZIP discs, DVD, etc. }\end{array}$ & $42(8.2)$ & $227(44.5)$ & 241(47.3) \\
\hline 16 & Scanner knowledge & $14(2.7)$ & $155(30.4)$ & $341(66.9)$ \\
\hline 17 & Knowledge of PDAs & 28(5.5) & $84(16.5)$ & $398(78.0)$ \\
\hline 18 & Deep web knowledge & $15(2.9)$ & $240(47.1)$ & $255(58.0)$ \\
\hline 19 & Knowledge on computer security & $15(2.9)$ & $240(47.1)$ & $255(58.0)$ \\
\hline 20 & Access to the internet from the faculty & $14(2.7)$ & $155(30.4)$ & $341(66.9)$ \\
\hline
\end{tabular}

Table 2 reveals the ICT fluency of the academics in ABU Zaria. Only 252 (44.4\%) are fluent in spread sheet packages. This shows that 258(50.6\%) of the academics lack knowledge of spreadsheet. This shows that more than half of the academics in ABU Zaria are not at home with spreadsheet programme. The academics should be able to use some type of spreadsheet programme to compile grades and chart data. When asked about database skills 241 (47.2\%) the academics are fluent in database. This shows that a majority of the academics are not fluent in database. This means that majority of the
Academics may not be able to interrogate online databases to perform searches. It is expected that Academics should be able to use some types of database to create tables, store and retrieve data, and query data. On Electronic presentation skills, such as power point $242(47.5 \%)$ of them are fluent in it. This shows that a majority of the academics may not be able to design a power point presentation independently. It is expected that Academics should be able to use electronic presentation software to crate and make electronic 
presentation. It was also discovered that 249(48.8\%) of the Academics in ABU Zaria are not fluent in web navigation. It therefore means that 261 (51.2\%) of them can not navigate and find online information from a variety of sources independently. Academics should be able to navigate the World Wide Web and search effectively for data on the Internet. On word processing skills $82(16.1 \%)$ of the Academic are very fluent with word processing. This shows that $359(70.4 \%)$ of the Academics are familiar with word processing and therefore can use it effectively to enhance their teaching and research. Academics should be able to use some types of word processing programmes to perform written task in a timely manner. Analysis on website Design skills reveals that $97(19.0 \%)$ of the Academics are very fluent. However a majority Academics in the study area lack techniques required to design a website or homepage. It is expected that Academics should be able to design, create, and maintain a faculty or personal webpage or website to enhance their chance of sharing information. It was also discovered that a majority of the Academics in the study area fluent in e-mail Management representing 258(50.6\%) response score. This shows that the academics can send messages to their colleagues through the web competently. It is expected that Academics should be able to use email to communicate and be able to send attachments and create e-mail folders.

The academics were asked to indicate their fluency in Digital cameras, network knowledge, downloading software from the web including ebooks, installation of computer software, web CT or Blackboard teaching skills. It was discovered that $101(19.8 \%), 67(13.1 \%), 83(16.3 \% 11(2.2 \%)$, and 30(5.9\%) respectively and 190(38.2), 162(31.8), 238(46.7), 162(31.8) and 05(1\%) claim to be fluent with them. The analysis shows that a majority of the Academics are deficient in the knowledge of Digital Cameras, Network knowledge, down loading software from the web including e-books, installation of computer software and web CT. Expectedly, Academics should know how to operate a digital camera and understood how digital imagery can be used; know the basics of computer networks and understood how their campus network works; be able to download software from the web and know the major sites that can be used for this purpose; be able to install computer software on to a computer system; be aware of those two online teaching skills web CT and Blackboard teaching skills and know about them and how to use them to teach or take classes. However, 26(51.8\%) of the Academics in ABU Zaria indicate fluency in file management and window explorer skills. It is expected that Academics should be able to manage their computer files and be able to create, and delete files and folders, move and copy files and folders using the MS computer window and window explorer.

It was also discovered that a majority of the academics were not fluent in video conferencing skills 326(63.9\%), computer related devices knowledge 24(47.3\%), scanner knowledge 341(66.9\%), PDA's knowledge 398(78.8\%), deep web knowledge 255(50.0\%) and computer security 341(66.9\%). Normally, academics should be able to use video conferencing classroom and understand the basics of teaching with video conferencing; understand how to use the following devices: discs, CDs, UBS drives, Zip disks and DVDs; know how to use scanner and what OCR capacity is; know what PDA is and how to use one; know about basic computer security issues to facilitate their teaching and research functions.

When asked about access to Internet from their faculty, a majority $341(66.9 \%)$ of them do not access Internet from their faculty offices. This finding is not a good development for academics and consequently, their access and productivity will be affected. Personal websites and home pages are good for sharing and accessing information globally and majority of the academics do not have them. The reason for this could be attributed to the observation of Mohammed (2006) that in Ahmadu Bello University, Zaria most of the departments cannot boast of having ICTs such as computers, internet connectivity, and other network facilities for teaching and research.

\section{Null hypothesis 1}

There is no significant difference among humanist, pure scientist, applied scientist and social scientist in their level of ICT literacy

From table 3a the calculated value of F3.779 was obtained and is greater than the table value 2.37 at the $\alpha=0.05$. The null hypothesis is therefore rejected and retained the null hypothesis. In order to determine the difference within the 4 disciplines with regards to the issue of ICT literacy, the data was further subjected to post hoc scheffe test for multiple comparisons. 
Table 3 (a): ICT literacy of the Academics

\begin{tabular}{|l|l|l|l|l|l|l|l|}
\hline $\begin{array}{l}\text { Sources of } \\
\text { Variance }\end{array}$ & DF & SS & MS & F-cal & P & F-crit & Remark \\
\hline $\begin{array}{l}\text { Between } \\
\text { Within }\end{array}$ & 4 & 73.963 & 18.491 & 3.779 & 0.005 & 2.37 & S \\
\hline Total & 505 & 2471.135 & 4.893 & & & & \\
\hline
\end{tabular}

$\mathrm{S}=$ Significant Difference

Table 3 (b) Post Hoc Scheffe Test Multiple Comparison of difference in ICT literacy between academic disciplines

\begin{tabular}{|ll|l|l|l|l|}
\hline Disciplines & & Mean Diff. & Std & Sig & $\begin{array}{l}\text { 95\% } \\
\text { interval }\end{array}$ \\
\hline (i) & (j) & I-J & Erronfidence \\
\cline { 1 - 2 } Pure science & Applied Sc & 0.450909 & 0.55134 & 0.952 & -1.2405 \\
& Sc. Sc. & -0.03918 & 0.62543 & 1.000 & -1.9728 \\
& Humanities & 0.027686 & 0.49259 & 0.0989 & -0.2461 \\
\hline Applied Sc. & Pure Sc. & -0.45909 & 0.55134 & 0.952 & -2.1637 \\
& Soc. Sc. & $-0.77554^{*}$ & 0.22669 & 0.021 & -1.4764 \\
& Humanities & $0.77554^{*}$ & 0.22669 & 0.021 & 0.0747 \\
\hline Soc. Sc. & Pure Sc. & 0.03918 & 1.62543 & 1.000 & -1.8944 \\
& Applied Sc. & 0.49828 & 0.50029 & 0.911 & -1.0485 \\
& Humanities & 0.31604 & 0.43469 & 0.971 & -1.0279 \\
\hline Humanities & Pure Sc. & -1.05240 & 0.50358 & 0.360 & -2.6093 \\
& Applied Sc. & $-0.77554^{*}$ & 0.22669 & 0.021 & -14764 \\
& Soc. Sci. & -1.09159 & 0.44711 & 1.204 & -2.4739 \\
\hline
\end{tabular}

* Significant Difference

Table 3(b) above shows the multiple comparisons of the ABU Academics' in their information literacy level ICT literacy and their discipline. The table reveals that there is a significant difference between science based disciplines such as pure and applied sciences and other disciplines. This means that ICT literacy level of academics' in pure and applied scientist is higher than that of their colleagues in social sciences and humanities. The reason for higher level of ICT of pure and applied scientists compared with other disciplines could be attributed to their ability to use all forms of media to ensure close interaction with their colleagues and to share their research findings. This confirmed the findings of Olabisi (1985) that pure scientist and applied scientist deliberately establish information networks to facilitate their significant breakthrough and to be productive in their fields.

From the table above, it can be deduced that the Humanist and Social Scientist in Ahmadu Bello University, Zaria under explore the available ICTs for teaching and research as a result of their low level of ICT literacy. They have limited access to important information that will help them in their teaching and research. Ideally, Academics in all disciplines are expected to show capacity to manipulate all sorts of ICT facilities to share information and be up to date in their various fields. The ABU Academics need to be motivated to possess ICT skills. So therefore there is the need for the university to provide ICT facilities for IL practice for the academics.

\section{Null Hypothesis 2}

There is no significant relationship between academic qualification of the academics and their level of ICT literacy. 
Table 4. : $\quad$ Relationship between Academic Qualification of ABU academics and their ICT Literacy

\begin{tabular}{|l|l|l|l|l|l|l|l|}
\hline Variables & Mean & SD & SE & R & Df & P & r-crt \\
\hline $\begin{array}{l}\text { Academic - } \\
\text { qualification } \\
\text { ICT literacy }\end{array}$ & 1.9667 & 0.77843 & 0.03447 & 0.072 & 508 & 0.106 & 0.088 \\
\hline
\end{tabular}

In order to test this hypothesis, the data was subjected to Pearson Product Moment Correlation (PPMC). The calculated value of 0.072 at the degree of freedom (df) of 508 and $\sigma 0.05$ was obtained. The calculated t-value of 0.072 is less than the table value of 0.088 at the same $\mathrm{df}$ and confidence level. It is therefore concluded that there is no significant relationship between academic qualification of the academics and their ICT level in Ahmadu Bello University, Zaria.

This finding contradicts the findings of Wanitskaya (2006) that in developed countries the higher the educational level the more fluent academics will be with ICT facilities. In Nigeria, this kind of finding is not unexpected since we witness the dearth of ICT facilities in our campuses, increase cut in university budgets, , and above all high rate of brain drain of senior academics in the country. This call for the attention of National University Commission, Federal Ministry of Education and the University Management to provide adequate ICT facilities in our universities to enable the academics harnesses the gains of digital world.

\section{Conclusion}

Information has become an important ingredient for effective decision making. Academics in the course of conducting their daily businesses generate large volume of data and information which culminated into different records which represent a collective memory of the organization. ICT on the other hand, has undoubtedly facilitate access and use of information and assist academics to generate, process, store, preserve, retrieve, access and disseminate information within and outside their institutions. It is hoped that academics and stake holders in education would employ information and communication technologies (ICTs) in teaching, learning and scholarship for sustainable growth and development. Information and communication technology is a pre-requisite for people and institutions to successfully survive and compete in the $21^{\text {st }}$ century and beyond. It can be concluded that for one to be relevant in a world where the written word dominates does not only require good writing and reading skills but also have the ability to think critically, to read between lines, share ideas and build collective action that will ensure mastery of
ICT skill, this will certainly have positive impact on teaching, learning and scholarship.

\section{Recommendations}

In the light of the findings of the study, it is therefore recommended that:

1. Information and Communication Technology literacy should be incorporated into the curriculum of Nigerian University. It should also be made one of the desired learning outcomes for graduation and also a criterion for promotion.

2. State of the Art ICT facilities (computers, scanners, digiatal cameras, PDA, telecommunication infrastructure and Internet) should be provided as a matter of urgency in all the faculties and staff offices in the university. This will make the Academics to appreciate the relevance of ICT in teaching and research. The academics would be up to date and more responsive to the challenges of their profession in this digital age.

3. The university libraries should establish effective and sustainable information and Communication Technology literacy programme. This will enhance location, access and evaluation of information resources in various formats.

4. Librarians, Academics and other stakeholders should be re-trained through refresher courses, symposia, meetings and workshops on the latest trend in ICT development.

5. Cooperative research and joint authorship with both local and international colleagues should be encouraged. This will ensure cross fertilization of ideas and enable them to share their expertise in information handling.

6. It would not be out of place if the academics were encouraged and motivated to own and maintain their own personal websites and homepages. The university authority should facilitate the creation and ownership of these sites by all the Academics. This will invariable enhance access, use and sharing of information.

7. Research supported by government, university management, library organisations and the private sector is required to identify long term academic and social gains of ICT based learning programmes, identity promising practices in teaching ICT where resources and information professionals are well established, developed educational models for achieving improve ICT 
Proficiency where resources and information professionals are not available, identify parameters for effective ICT based professional development and its long term effects on Academics, focus on evidence-based practice as fundamental tool in teaching, monitoring and evaluating local Information and Communication Technology literacy initiatives.

8. More funds should be allocated to university libraries to enable them respond to their changing role of re-orienting the information users on the latest development in ICT practices.

\section{References}

Abduljabbar, K. (2003) 'Information Communication Technologies (ICTs) and its Management for Sustainable Development. Paper Presented on Uses of Information Communication Technology $2^{\text {nd }}-4^{\text {th }}$ May.

Adedokun, O. A. et al (2006). "Adoption of Information Communication Technologies (ICTs) in Nigeria: Problems and Prospects for Rural Youth" A Paper presented at the annual meeting of the Rural Sociological Society, Seelbach Hilton Hotel, Louisville, Kentucky. 2008-06-26 from http://www.allacademic.com/meta/p124896_inde $\mathrm{X} . \mathrm{html}$

Economic and Social Commission for Asia and the Pacific (ESCAP) (2000). "Are ICT Policies Addressing Gender Equality?” Retrieved 23/06/2010 from http//www unescaporg/wid/04w i d r e s o u r c e s / 11 wi d e a c t i v i t e s / 01 c c t e g m /backgroundpaper. Pdf.

Griffin, R.W. (1999). Management, US; Houghton Mifflin Co. Sixth edition, p.101

Healthcote, P. M. (2002) 'A' level Information Communication Technology. $2^{\text {nd }}$ ed. Great Britain: Payne-Gallway, p.45.

Well, C. \& Lundall, P. (2000). "Computers in Schools: A National Survey of Information
Communication Technology in South African Schools”. Education Policy Unit. Cape Town: University of the Western Cape, Retrieved 2/07/2010 from http://www.school.za/schoolsurveys/suveys_inde x.htm

Mohammed, Zakari (2006). The Library and Information Science Research in Nigeria. Mimeograph.

Musa, A. I. (2007). “Awareness, Adoption and Use of Information and Communication Technologies by Small and Meduim Size Enterprises: An Exploratory Survey of Northern Nigeria” in Journal of Educational Research and Development. A journal of the faculty of education, A. B. U. Zaria. Vol.2 No.3 p.216.

OECD (1996). The knowledge based economy. Paris: OECD.

OECD (2000). Learning to bridge the digital divide. Paris: OECD.

OECD (2001). Educational policy analysis 2001. Paris: OECD, Centre for Educational Research and Innovation.

OECD (2001). Learning to change: ICT in Schools. Paris: OECD

OECD (2001). Cities and regions in the new learning economy. Paris: OECD.

OECD and Statistics Canada (2000). "Literacy in the information age," final report of the international adult literacy survey. Paris: OECD and Statistics Canada

Olatokun, Wole Micheal (2007). “Adoption and Use of ICTs in Manufacturing Industry: A Preliminary Survey”. In The Information Technologist vol. 4, 1 p.14

Ivanitskaya, Lana (2006). Health Information Literacy and Competencies of Information Age Academics: Results from the Interactive Online Research Readiness Self Assessment (RRSA). Journal of Medical Internet Resources. Vol. 8(2). 